The Journal of Bone E Joint Surgery
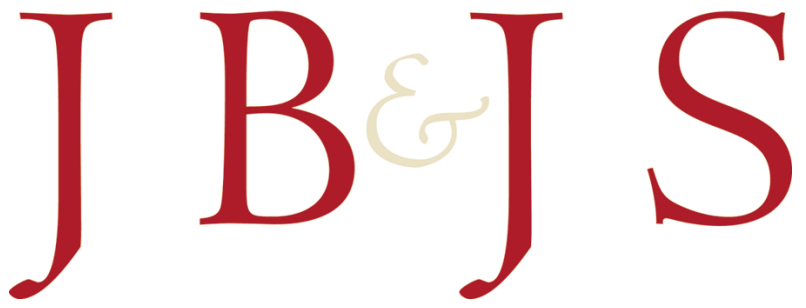

This is an enhanced PDF from The Journal of Bone and Joint Surgery

The PDF of the article you requested follows this cover page.

\title{
Comparison of Three Different Pelvic Circumferential Compression Devices: A Biomechanical Cadaver Study
}

S.P. Knops, N.W.L. Schep, C.W. Spoor, M.P.J.M. van Riel, W.R. Spanjersberg, G.J. Kleinrensink, E.M.M. van Lieshout, P. Patka and I.B. Schipper

J Bone Joint Surg Am. 2011;93:230-240. published Dec 30, 2010; doi:10.2106/JBJS.J.00084

This information is current as of February 21, 2011

Reprints and Permissions

Publisher Information
Click here to order reprints or request permission to use material from this article, or locate the article citation on jbjs.org and click on the [Reprints and Permissions] link.

The Journal of Bone and Joint Surgery

20 Pickering Street, Needham, MA 02492-3157

www.jbjs.org 


\title{
Comparison of Three Different Pelvic Circumferential Compression Devices: A Biomechanical Cadaver Study
}

\author{
By S.P. Knops, MSc, N.W.L. Schep, MD, PhD, MSc, C.W. Spoor, PhD, M.P.J.M. van Riel, MSc, W.R. Spanjersberg, MD, \\ G.J. Kleinrensink, PhD, E.M.M. van Lieshout, PhD, P. Patka, MD, PhD, and I.B. Schipper, MD, PhD \\ Investigation performed at Erasmus MC, University Medical Center Rotterdam, Rotterdam, The Netherlands
}

\begin{abstract}
Background: Pelvic circumferential compression devices are designed to stabilize the pelvic ring and reduce the volume of the pelvis following trauma. It is uncertain whether pelvic circumferential compression devices can be safely applied for all types of pelvic fractures because the effects of the devices on the reduction of fracture fragments are unknown. The aim of this study was to compare the effects of circumferential compression devices on the dynamic realignment and final reduction of the pelvic fractures as a measure of the quality of reduction.
\end{abstract}

Methods: Three circumferential compression devices were evaluated: the Pelvic Binder, the SAM Sling, and the T-POD. In sixteen cadavers, four fracture types were generated according to the Tile classification system. Infrared retroreflective markers were fixed in the different fracture fragments of each pelvis. The circumferential compression device was applied sequentially in a randomized order with gradually increasing forces applied. Fracture fragment movement was studied with use of a three-dimensional infrared video system. Dynamic realignment and final reduction of the fracture fragments during closure of the circumferential compression devices were determined. A factorial repeated-measures analysis of variance with pairwise post hoc comparisons was performed to analyze the differences in pulling force between the circumferential compression devices.

Results: In the partially stable and unstable (Tile type-B and C) pelvic fractures, all circumferential compression devices accomplished closure of the pelvic ring and consequently reduced the pelvic volume. No adverse fracture displacement $(>5 \mathrm{~mm})$ was observed in these fracture types. The required pulling force to attain complete reduction at the symphysis pubis varied substantially among the three different circumferential compression devices, with a mean (and standard error of the mean) of $43 \pm 7 \mathrm{~N}$ for the T-POD, $60 \pm 9 \mathrm{~N}$ for the Pelvic Binder, and $112 \pm 10 \mathrm{~N}$ for the SAM Sling.

Conclusions: The Pelvic Binder, SAM Sling, and T-POD provided sufficient reduction in partially stable and unstable (Tile type-B1 and C) pelvic fractures. No undesirable overreduction was noted. The pulling force that was needed to attain complete reduction of the fracture parts varied significantly among the three devices, with the T-POD requiring the lowest pulling force for fracture reduction.

Clinical Relevance: The results of this biomechanical cadaver study suggest that circumferential compression devices can provide early, noninvasive circumferential compression in partially stable and unstable pelvic fractures for advantageous realignment and reduction of these fractures without overreduction. Clinical effectiveness of circumferential compression devices in patients with pelvic ring fractures remains to be determined.

$\mathrm{P}$ elvic fractures following high-energy trauma are frequently accompanied by massive hemorrhage and are considered potentially lethal injuries. Reported mortality rates for trauma patients with pelvic fractures have ranged from $5 \%$ to $55 \%$, depending on the fracture type and overall injury severity ${ }^{1,2}$. It is commonly accepted that anatomic reduction and stabilization of pelvic fractures prevents further blood loss by limiting the bleeding from the fracture fragments and reducing the pelvic volume. In the majority of patients, the bleeding source is the injured sacral venous plexus or bone

Disclosure: The authors did not receive any outside funding or grants in support of their research for or preparation of this work. Neither they nor a member of their immediate families received payments or other benefits or a commitment or agreement to provide such benefits from a commercial entity. 
The Journal of Bone \& Joint Surgery · Jbjs.org Volume 93-A - Number 3 - February 2, 2011
Comparison of Three Different Pelvic

Circumferential Compression Devices surfaces. Reducing the pelvic volume may therefore have a tamponading effect ${ }^{3,4}$ and may consequently decrease blood loss and transfusion requirements ${ }^{5}$.

Early reduction and stabilization of pelvic fractures may lead to less blood loss and improved patient survival. This early reduction and stabilization should preferably be achieved at the scene of the accident and, at the latest, on arrival at the emergency department. Both invasive and noninvasive treatment modalities have been described ${ }^{3,5,6}$. However, invasive methods like the $C$ clamp $^{7-10}$ and external fixators ${ }^{11,12}$ are not feasible at the injury scene because application requires emergency department or operating-room facilities. Even in the hospital setting, these invasive measures often take considerable time to apply. Hence, various methods of early, fast, and noninvasive pelvic fracture stabilization have been applied. The most commonly known methods are bed-sheet wrapping ${ }^{13,14}$, internal rotation and taping of the lower extremities $^{15}$, and, more recently, the application of a pelvic circumferential compression device ${ }^{3,16-26}$. Pelvic circumferential compression devices are commercially available pelvic wraps designed to stabilize the pelvic ring and to reduce the volume of the pelvis by controlled external circumferential compression.

Limited data are available on the efficacy of the pelvic circumferential compression devices. To our knowledge, only Level-III evidence ${ }^{27}$ concerning their efficacy has been reported $^{16}$. In a prospective cohort study, Krieg et al. described sixteen patients with partially stable and unstable pelvic ring fractures ${ }^{3}$. In the patient group with externally rotated fractures, the pelvic circumferential compression device significantly reduced the pelvic width. In the internal rotation group, the device did not cause overcompression. As it is unclear whether patients were consecutively included, a selection bias cannot be ruled out. Until now, the quality of reduction provided by the pelvic circumferential compression device for all types of pelvic fractures is uncertain, since the effect of the device on the position of the fracture fragments is unknown.

Before undertaking clinical trials, it is essential to establish the biomechanical effects of these devices through laboratory experiments. Therefore, the aim of this cadaver study was to compare the effects of three commercially available pelvic circumferential compression devices on the dynamic realignment and final reduction of pelvic fracture fragments. These effects were considered a measure of the quality of reduction provided by the devices.

\section{Materials and Methods}

biomechanical cadaver study aimed to determine the quality A of reduction induced by the pelvic circumferential compression devices in relation to the pulling force required for proper application. Three commercially available pelvic circumferential compression devices were evaluated: the Pelvic Binder (Pelvic Binder, Dallas, Texas), the SAM Sling (SAM Medical

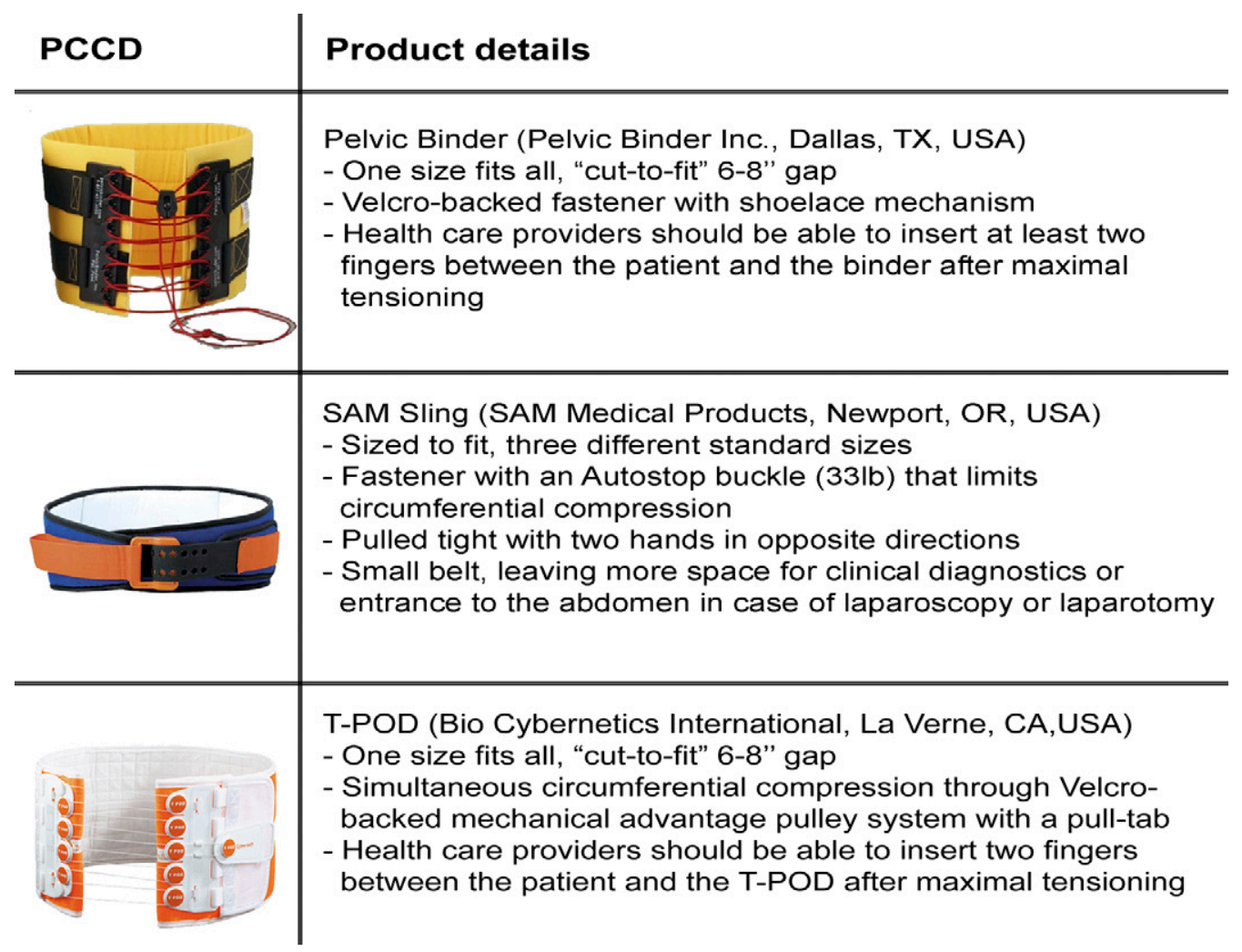

Fig. 1

The three commercially available pelvic circumferential compression devices evaluated in this study (Pelvic Binder, SAM Sling, and T-POD) with the product details and manufacturers' guidelines for their application. 
The Journal of Bone \& Joint Surgery · Jbjs.org Volume 93-A • Number $3 \cdot$ February 2, 2011
Comparison of Three Different Pelvic

Circumferential Compression Devices
Products, Wilsonville, Oregon), and the Trauma Pelvic Orthotic Device (T-POD; Bio Cybernetics International, La Verne, California) (Fig. 1). The three available sizes of the SAM Sling (extra small, standard, and extra large) were used when indicated.

Ten male and six female cadavers without a known history of pelvic fractures were randomly selected. The cadavers were embalmed forty-eight to seventy-two hours post mortem at room temperature, with use of a $6 \%$ paraformaldehyde solution. The specimens consisted of the complete pelvic region including all soft tissues, from the level of the third or fourth lumbar vertebral body and including the proximal two-thirds of both femora.

In order to identify anatomic regions and fracture fragments of the osseous pelvis, stainless steel pins, each with five retroreflective markers, were firmly fixed adjacent to planned fracture lines (Fig. 2, A). The pins were placed under fluoroscopic guidance close to the sacroiliac joint, close to the symphysis pubis, and on either side of the created fractures in the iliac and pubic bones. Pin position was confirmed with anteroposterior, inlet, and outlet fluoroscopic views. The pins remained in place during application of the pelvic circumfer- ential compression devices, which were rigidly fixed into the bone. Coordinates of the retroreflective markers were recorded with use of a Vicon system (Vicon Motion Systems, Oxford, United Kingdom). The specimens were mounted in a custommade frame on a platform, and the proximal lumbar vertebral body was screw-fixed with a lumbar clamp to ensure standardized measuring (Fig. 2, $B$ and $C$ ). Light emitted by infrared light-emitting diodes was captured by the cameras on reflection from the retroreflective markers placed at the fracture sites (Fig. 2, $C$ and $D$ ). Prior to each measuring session, static and dynamic calibrations were carried out according to the Vicon instruction manual. Static calibration was used to set the origin and the direction of the axes, and dynamic calibration was used to calculate the relative positions and orientation of the cameras.

First, pins with retroreflective markers were placed in unfractured pelves. Subsequently, reference measurements were performed to establish the exact positions of the ilium, sacrum, and pubis in the unfractured state. Subsequently, all sixteen pelves were osteotomized to simulate fractures in randomized order with the pins and retroreflective markers in

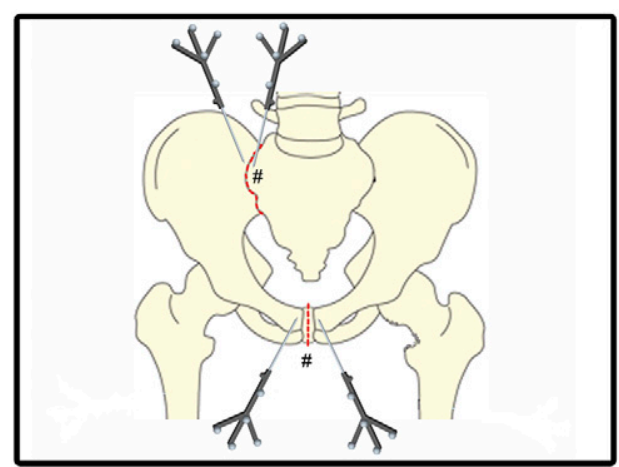

A



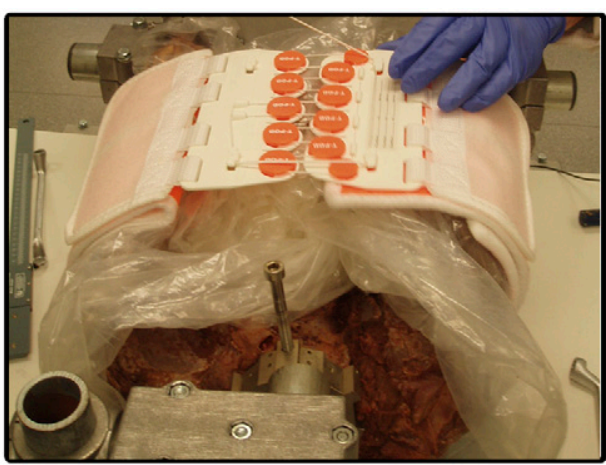

B

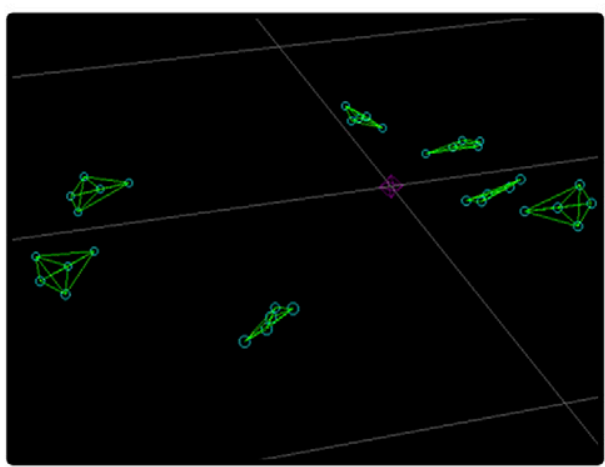

D

Overview of the measurement setting. A: Placement of stainless steel pins with five retroreflective markers close to the planned fracture sites for a Tile type-B1 fracture (fracture lines are indicated in red). Pins were placed close to planned fracture sites for all different fracture types and remained in place until the end of measurements. B: A pelvic specimen screw-fixed with a lumbar clamp at the proximal lumbar vertebral body, with placement and tensioning of a pelvic circumferential compression device (T-POD). C: Pelvic specimen with retroreflective markers fixed in a custom-made frame. D: Visualization of a measurement with the Vicon software. 


\begin{tabular}{l|l|l} 
Classification & Stability & Study definition \\
\hline Tile A & Stable & $\begin{array}{l}\text { A fracture in the os pubis } \\
\text { was created } 2 \text { cm lateral } \\
\text { from the symphysis pubis } \\
\text { combined with a large } \\
\text { fracture of the os ilium, } \\
\text { ranging from the spina } \\
\text { iliaca up to the tuber }\end{array}$ \\
$\begin{array}{l}\text { Tile B1 } \\
(100 \mathrm{~mm})\end{array}$ & Partially & $\begin{array}{l}\text { A fracture in the os pubis } \\
\text { was created through the } \\
\text { symphysis pubis and } \\
\text { displaced (50 or } 100 \text { mm) } \\
\text { with a Finochietto rib } \\
\text { spreader, causing unilateral } \\
\text { rupture of the anterior liga- } \\
\text { ments of the Sl-joint }\end{array}$ \\
\hline Tile C & Unstable & $\begin{array}{l}\text { Complete pelvic ring } \\
\text { instability was created } \\
\text { through a fracture of the } \\
\text { os pubis and a unilateral } \\
\text { rupture of the SI-joint, } \\
\text { including disruption of the } \\
\text { soft tissue and rupture of } \\
\text { the sacroiliac and sacro- } \\
\text { tuberous ligaments }\end{array}$ \\
\hline
\end{tabular}

Fig. 3

The study definitions of the pelvic fractures according to the classification system of Tile et al. The fractures were classified by the principal fracture, and the classification was based on the direction (pathomechanics) of the impact force that caused the trauma and the progressive instability of the pelvic ring. A schematic representation of the study definition of the fractured pelves in this cadaveric study is shown in the right column. The red dashed lines indicate the fracture lines. SI = sacroiliac.

place. All fractures were created according to the study definition on the basis of the Tile classification ${ }^{28}$ (i.e., four type-A fractures, four type- $\mathrm{B} 1$ fractures with a $50-\mathrm{mm}$ pubic diastasis, four type-B1 fractures with a $100-\mathrm{mm}$ pubic diastasis, and four type-C fractures) (Fig. 3). All fractures were produced with an osteotome, and diastasis was achieved with a Finochietto rib spreader placed between the symphysis pubis. In the type-B1 fractures, two widths of diastasis were created to differentiate between a mild and a severe disruption of the pelvic ring at trauma. Prior to each new measurement with a different pelvic circumferential compression device, a rib spreader was used to create sufficient diastasis. The soft-tissue envelope was preserved whenever possible. Fracture subtypes were confirmed with use of anteroposterior, inlet, and outlet fluoroscopic images.

Subsequently, the specimens were placed on the platform and the three pelvic circumferential compression devices were successively applied in randomized order. The pelvic circumferential compression devices were applied at the level of the greater trochanters ${ }^{29}$ and were tensioned according to the manufacturer's guidelines (Fig. 1). A stepwise (20 N per step) increased pulling force was applied, measured with a digital force gauge (9000 series CPU; AIKOH Engineering, Osaka, Japan). This pulling force was increased until the pelvic circumferential compression device was fitted according to the manufacturer's recommendations (Fig. 1). With the Pelvic Binder and the T-POD, two fingers were inserted between the specimen and the device. From the digital force gauge, it could be read that the Pelvic Binder and the T-POD were tensioned to a maximum of 120 and $100 \mathrm{~N}$, respectively. The SAM Sling was pulled tight with two hands in opposite directions and the fastener with the Autostop buckle limited the circumferential compression at a strap tension of $150 \mathrm{~N}$.

During tensioning, the three-dimensional positions of the fracture fragment markers were recorded in real time with the Vicon system (Fig. 2, D). All marker positions were transformed to a single orthogonal coordinate system (Fig. 4), with the blue $\mathrm{X}$-axis indicating movement in the caudocranial direction; the red Y-axis, the mediolateral direction; and the green $\mathrm{Z}$-axis, the posteroanterior direction.

The marker coordinates were processed with MATLAB software (version 7.1; The MathWorks, Natick, Massachusetts). Comparison of the unfractured pelvis set with the fractured pelvis set showed the displacement of pin points was caused by fracturing and application of pelvic circumferential compression devices, with this displacement representing displacement at fracture sites. The pin-point displacements (in millimeters) of the fragments after application and tensioning of the pelvic circumferential compression devices, relative to their reference 


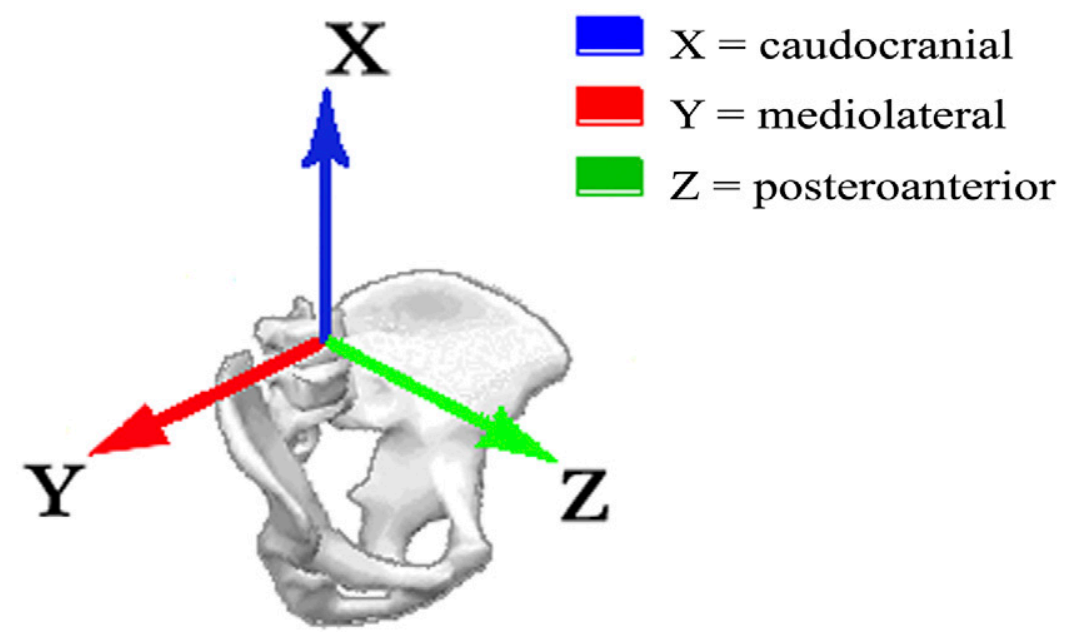

Fig. 4

The orthogonal system used to describe the movements of the fracture fragments in three directions. The blue $\mathrm{X}$-axis represents the caudocranial direction, the red $\mathrm{Y}$-axis represents the mediolateral direction, and the green Z-axis represents the posteroanterior direction.

positions, were used as a measure of quality of reduction. Differences in pulling force between the pelvic circumferential compression devices that was needed to reach reduction at the symphysis in Tile type-B1 and C fractures were analyzed. Reduction was defined as the lowest amount of diastasis at the symphysis. However, diastasis of $\leq 10 \mathrm{~mm}$ is considered nor$\mathrm{mal}^{20}$ and unlikely to be clinically relevant; in this study, diastasis of $<5 \mathrm{~mm}$ was considered acceptable. The results were visualized with GraphPad Prism (version 4.00; GraphPad Software, La Jolla, California).

\section{Statistical Methods}

No preliminary or published data that could be used to calculate the required sample size existed. Therefore, initial measurements were restricted to four cadaveric specimens with a Tile type-A fracture, eight with a Tile type-B fracture, and four with a Tile type- $C$ fracture, for all three pelvic circumferential compression devices. Statistical analysis was performed with use of the Statistical Package for the Social Sciences software (version 16.0; SPSS, Chicago, Illinois). A factorial repeated-measures analysis of variance was performed to analyze the differences among the pelvic circumferential compression devices with regard to the pulling force required to reach reduction at the symphysis. The Mauchly test was used to test the assumption of sphericity. Post hoc pairwise comparison tests with Bonferroni correction were used to test the differences between group means.

\section{Source of Funding}

There was no external financial funding source for this study. The pelvic circumferential compression devices used for this study were provided by Pelvic Binder (Pelvic Binder), Innoventa BV (SAM Sling), and Rescue 3000 BV (T-POD). Neither the companies providing the pelvic circumferential compression devices nor the device manufacturers played a role in this study.

\section{Results}

$\mathrm{C}$ igure 5 shows the displacements relative to the reference F position in a Tile type-B1 (50-mm diastasis) fracture before and during tensioning of a T-POD. On application of an increasing pulling force, the displacements of the fracture fragments reduced to $<1 \mathrm{~mm}$ in caudocranial $(\mathrm{X})$, mediolateral $(\mathrm{Y})$, and posteroanterior $(\mathrm{Z})$ directions. All pelvic circumferential compression devices were evaluated in this manner in all pelvic fractures.

The combined results (four per fracture type) of the measurements are presented in Figures 6-A through 6-D. The average displacements in all three directions and the corresponding standard error of the mean (SEM) of the fractured pelves are presented adjacent to all three pelvic circumferential compression devices.

\section{Tile Type A}

In Tile type-A fractures (Fig. 6-A), the average displacement of the pubic and iliac bones was $<5 \mathrm{~mm}$ in all three directions before tensioning of the pelvic circumferential compression devices. Tensioning the devices according to the manufacturers' guidelines resulted in an overreduction of $<5 \mathrm{~mm}$ in the medial direction at the pubis. Following tensioning of the Pelvic Binder, an average posterior displacement of $5.96 \pm 2.59 \mathrm{~mm}$ was found at the ilium. The average displacement at the ilium for the SAM Sling and T-POD was $<5 \mathrm{~mm}$.

\section{Tile Type B1 $(50 \mathrm{~mm})$}

Tile type-B1 fractures with a 50-mm pubic diastasis (Fig. 6-B) resulted in an average diastasis of $18.87 \pm 5.59 \mathrm{~mm}$ at the symphysis pubis before tensioning of the pelvic circumferential compression devices. The displacement in the mediolateral direction at the symphysis pubis during tensioning showed a gradual decline of the diastasis with each step of 20-N applied force. Average pulling forces of $60 \mathrm{~N}$ (Pelvic Binder), $120 \mathrm{~N}$ 
A

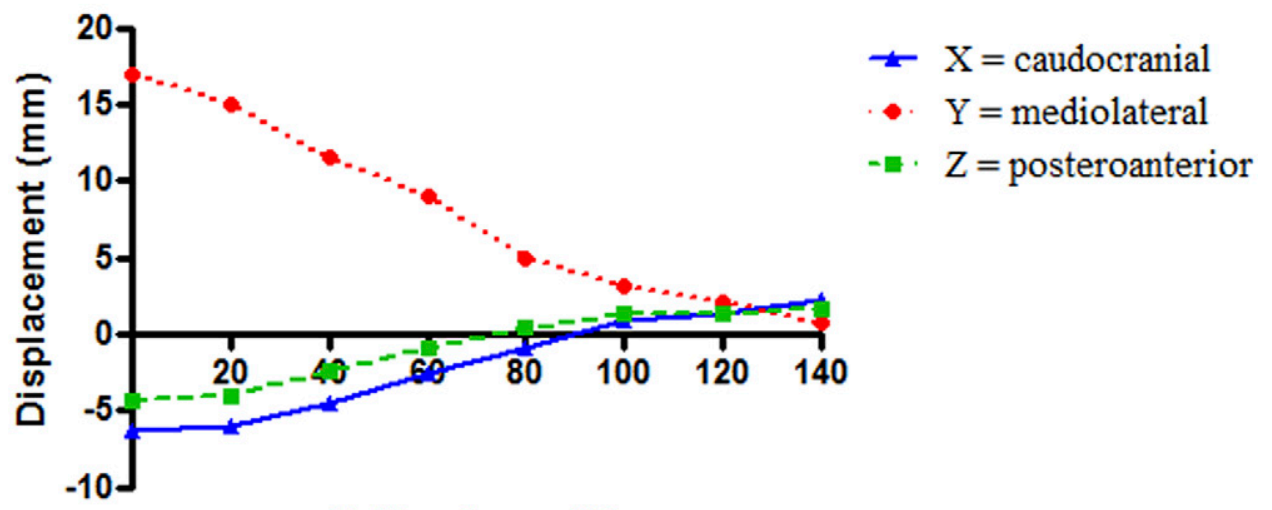

Pulling force (N)

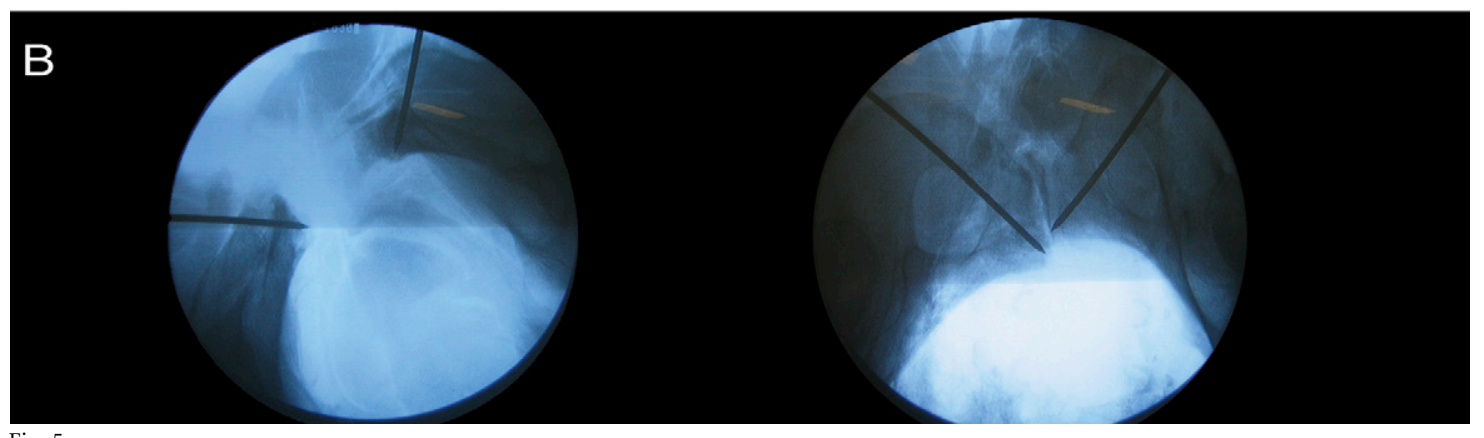

Fig. 5

An example of the reduction of the displacement of a Tile type-B1 (50-mm) fracture at the symphysis pubis before and during tensioning of a T-POD device. A: Displacements of fracture fragments in the $\mathrm{X}, \mathrm{Y}$, and $\mathrm{Z}$ directions. The reduction of the fracture fragments is shown in all three directions during tensioning of the pelvic circumferential compression device. $B$ : Anteroposterior radiographs showing displacement of the fracture fragments and pin position before tensioning (left panel) and reduction of the fracture fragments after tensioning of the device (right panel).

(SAM Sling), and $40 \mathrm{~N}$ (T-POD) were needed to reduce the lateral displacement to the reference position. A pulling force according to the manufacturers' guidelines resulted in a medial overreduction of $<5 \mathrm{~mm}$ at the symphysis pubis for all devices. At the location of the sacroiliac joint, the displacement in all three directions was $<5 \mathrm{~mm}$ before and after tensioning the devices.

\section{Tile Type $B 1(100 \mathrm{~mm})$}

The Tile type- $\mathrm{B} 1$ fractures with $100-\mathrm{mm}$ pubic diastasis (Fig. 6-C) were characterized by an average diastasis of $20.44 \pm$ $2.42 \mathrm{~mm}$ at the symphysis pubis. Similar to the type-B1 (50-mm) fractures, a gradual diastasis reduction per step of $20 \mathrm{~N}$ was observed in the mediolateral direction. Applying a pulling force according to the manufacturers' guidelines resulted in an average diastasis at the symphysis pubis of $<5 \mathrm{~mm}$ for the Pelvic Binder and T-POD and $6.70 \pm 1.55 \mathrm{~mm}$ for the SAM Sling. The average displacement at the sacroiliac joint in either direction remained $<5 \mathrm{~mm}$ for all devices.

\section{Tile Type C}

Before tensioning of the pelvic circumferential compression devices, the average displacement at the symphysis pubis in the
Tile type-C fractures (Fig. 6-D) was $1.38 \pm 4.58 \mathrm{~mm}$ cranially, $15.26 \pm 3.51 \mathrm{~mm}$ laterally, and $5.45 \pm 2.30 \mathrm{~mm}$ anteriorly. The negative posteroanterior displacement at the symphysis pubis and the sacroiliac joint indicated a displacement of the fractured hemipelvis in an anterior direction.

Tile type- $\mathrm{C}$ fractures resulted in an average displacement of $<5 \mathrm{~mm}$ at the sacroiliac joint in all three directions before tensioning. An average pulling force of $60 \mathrm{~N}$ (Pelvic Binder and T-POD) and $100 \mathrm{~N}$ (SAM Sling) was necessary to reduce the lateral displacement at the symphysis pubis to the reference position. At the location of the symphysis pubis, tensioning of the pelvic circumferential compression devices according to the manufacturers' guidelines resulted in an overreduction. For the Pelvic Binder, the average overreduction was $0.08 \pm 4.67 \mathrm{~mm}$ caudally, $2.57 \pm 1.53 \mathrm{~mm}$ medially, and $5.07 \pm 3.11 \mathrm{~mm}$ anteriorly. For the SAM Sling, the average overreduction was $1.38 \pm$ $4.10,4.69 \pm 1.78$, and $5.06 \pm 3.66 \mathrm{~mm}$, respectively. For the T-POD, the average overreduction was $1.26 \pm 5.15,4.28 \pm 2.33$, and $5.74 \pm 3.66 \mathrm{~mm}$, respectively. The anterior displacement at the symphysis pubis ( 5 to $6 \mathrm{~mm}$ ) was unaffected by any of the pelvic circumferential compression devices. At the sacroiliac joint, tensioning according to manufacturers' guidelines resulted in an average cranial displacement of $0.02 \pm 1.30 \mathrm{~mm}$, an 
A Tile $A$ fractures
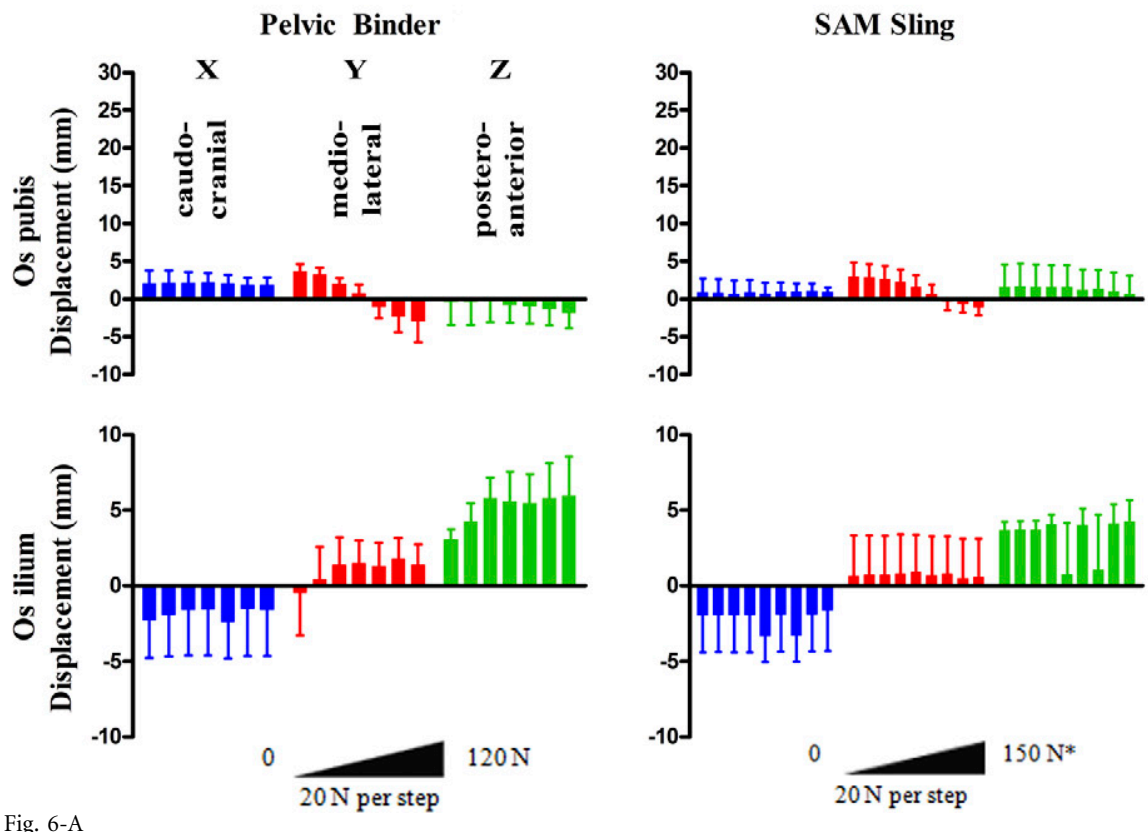

T-POD

\section{B Tile B1 $(50 \mathrm{~mm})$ fractures}

Pelvic Binder
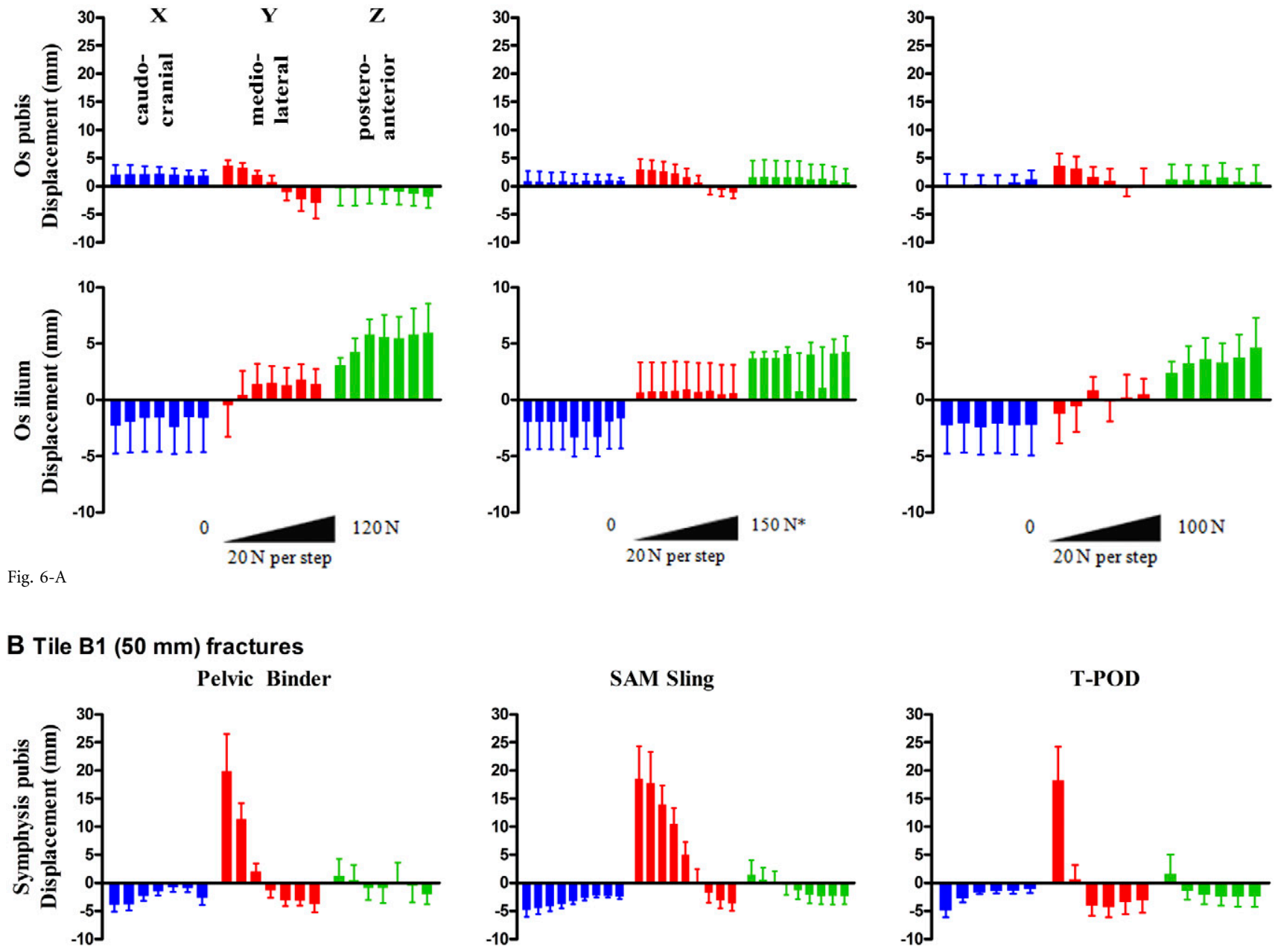

T-POD
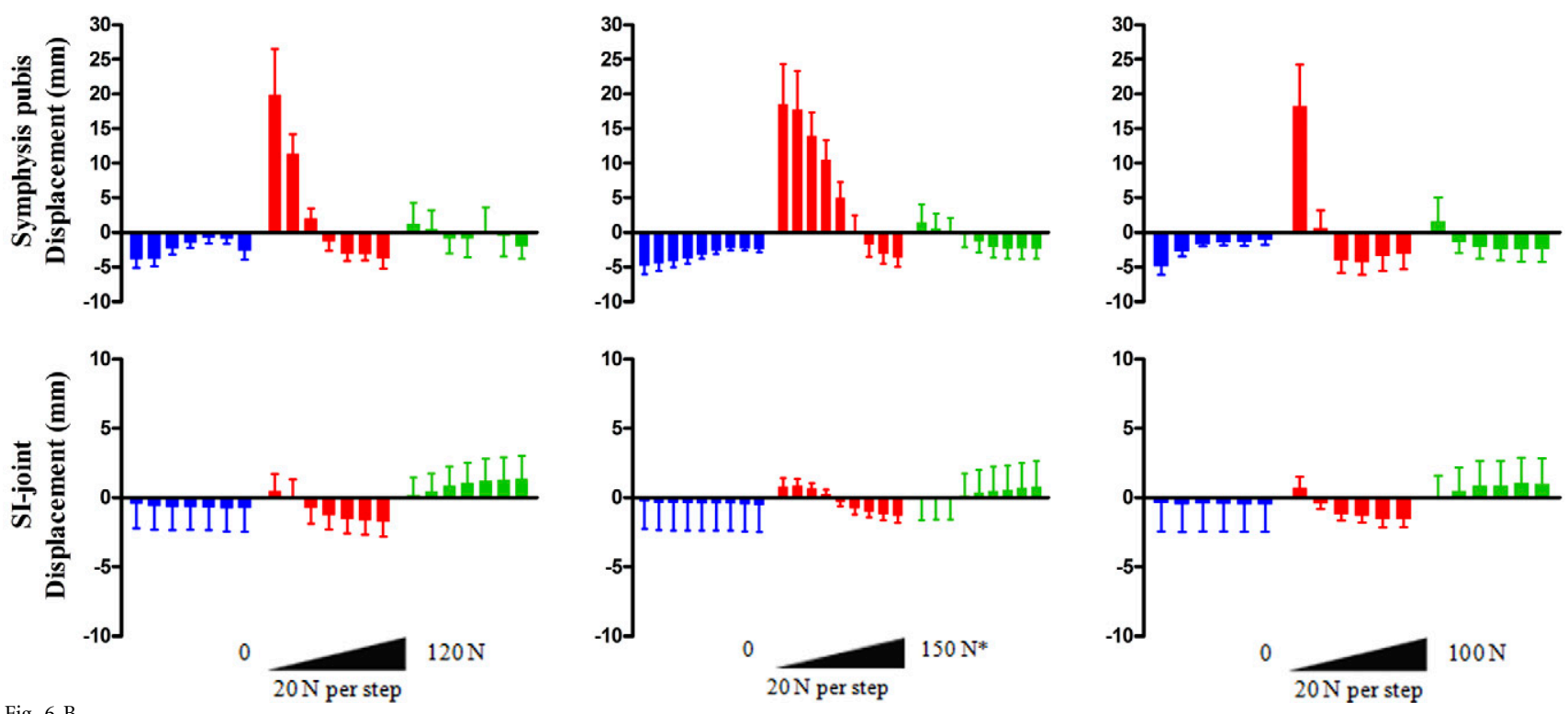

Figs. 6-A through 6-D Movements of pelvic fracture fragments after application of pelvic circumferential compression devices at the symphysis pubis (upper panel) and the ilium (lower panel) in Tile type-A fractures (Fig. 6-A), at the symphysis pubis (upper panel) and the sacroiliac (SI) joint (lower panel) in Tile type-B1 (50-mm) fractures (Fig. 6-B), at the symphysis pubis (upper panel) and the sacroiliac joint (lower panel) in Tile type-B1 (100-mm) fractures (Fig. 6-C), and at the symphysis pubis (upper panel) and the sacroiliac joint (lower panel) in Tile type-C fractures (Fig. 6-D). The combined results (four per fracture type) of the application of the Pelvic Binder (left panels), SAM Sling (middle panels), and T-POD (right panels) are presented. Data are given as the mean and the standard error of the mean. The Y-axis shows the displacement (in millimeters) relative to the reference position in the unfractured pelvis. A Y-axis value of zero represents the "anatomic" position. Positive caudocranial displacement (blue bars) means that the lateral pelvic part moved cranially relative to the medial part, positive mediolateral displacement (red bars) means that the lateral part moved laterally, and positive posteroanterior displacement (green bars) means that lateral part moved anteriorly. The X-axis shows the mean pulling force $(\mathrm{N})$ with a categorical 20-N interval and the last bar of each direction ends with $120 \mathrm{~N}, 150 \mathrm{~N}$, and $100 \mathrm{~N}$ for the Pelvic Binder, the SAM Sling, and the T-POD, respectively. The maximum force value of $150 \mathrm{~N}(*)$ is due to the SAM Sling Autostop buckle. 


\section{Tile B1 $(100 \mathrm{~mm})$ fractures}

Pelvic Binder


Fig $6 . C$

\section{Tile C fractures}

Pelvic Binder
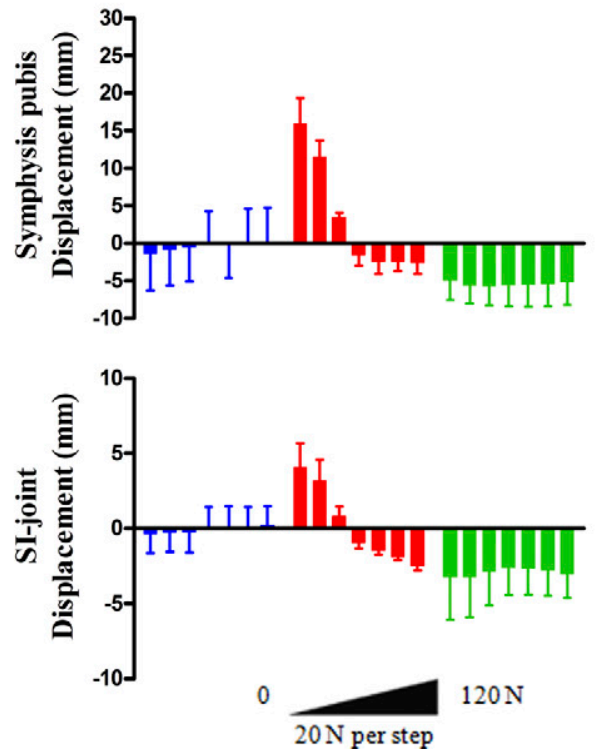

Fig. 6-D average overreduction of $2.09 \pm 0.57 \mathrm{~mm}$ medially, and displacement of $2.34 \pm 1.75 \mathrm{~mm}$ anteriorly.

The average pulling force required to reach the same position of the symphysis pubis as that in the unfractured, reference measurement in Tile type-B1 and $\mathrm{C}$ fractures was $60 \pm 9 \mathrm{~N}$ for the Pelvic Binder, $112 \pm 10 \mathrm{~N}$ for the SAM Sling, and $43 \pm 7 \mathrm{~N}$ for the T-POD. The Mauchly test had a $\mathrm{p}$ value of 0.04 , indicating violation of sphericity. Therefore, a GreenhouseGeisser corrected F statistic was used. The F value was 43.7 ( $\mathrm{p}<$ 0.01 ), which indicates a significant difference in pulling force
SAM Sling

T-POD
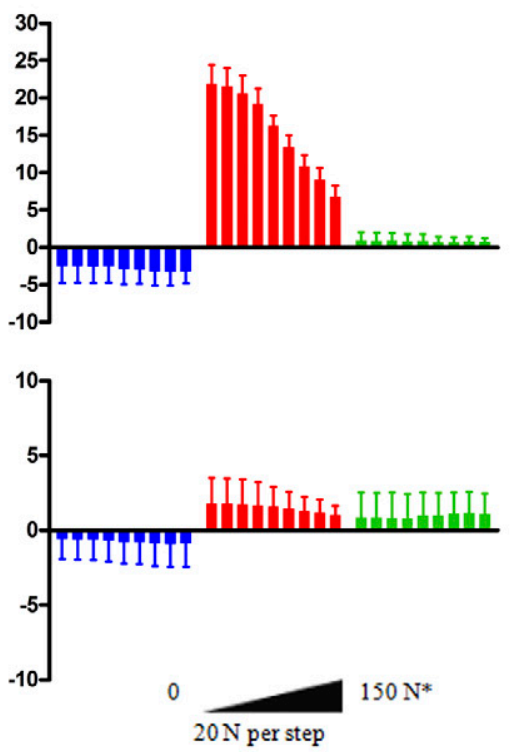

SAM Sling
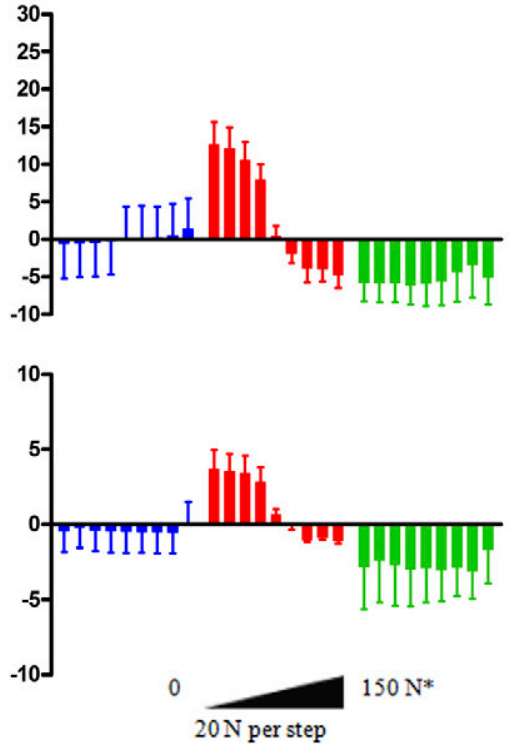
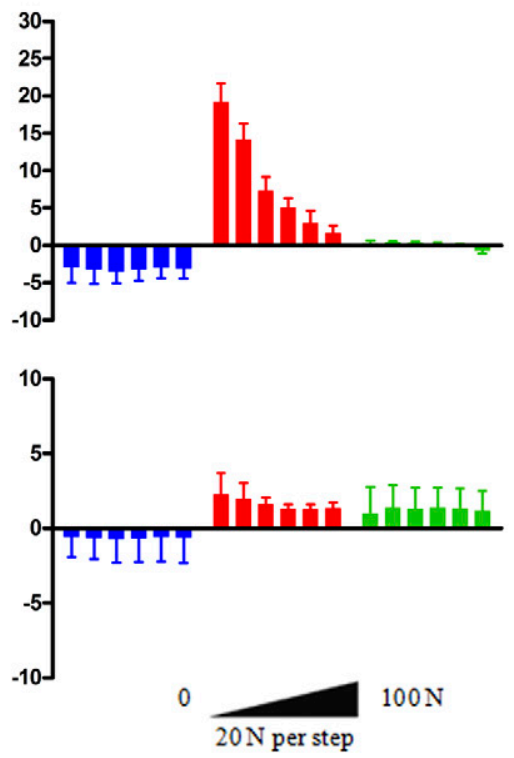

T-POD

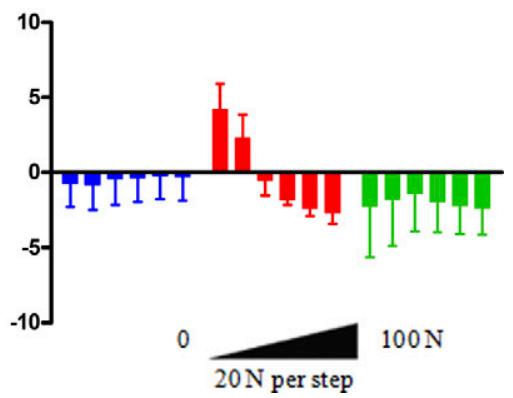

among the different pelvic circumferential compression devices. Between-group post hoc tests showed that the average required pulling force to attain complete reduction was $52 \pm$ $6 \mathrm{~N}$ lower for the Pelvic Binder than the SAM Sling $(\mathrm{p}<0.01)$, $17 \pm 6 \mathrm{~N}$ higher for the Pelvic Binder than the T-POD $(\mathrm{p}=$ $0.05)$, and $68 \pm 10 \mathrm{~N}$ higher for the SAM Sling than the T-POD $(p<0.01)$. The average symphysis diastasis reduction for the Tile type-B1 and C fractures was $19.64 \pm 2.86 \mathrm{~mm}$ for the Pelvic Binder, $18.18 \pm 2.25 \mathrm{~mm}$ for the SAM Sling, and $20.11 \pm$ $2.87 \mathrm{~mm}$ for the T-POD. The average diastasis reduction was 
The Journal of Bone \& Joint Surgery · Jbjs.org Volume 93-A - Number $3 \cdot$ February 2, 2011
Comparison of Three Different Pelvic

Circumferential Compression Devices similar for all three binders (Greenhouse-Geisser F value, 1.7; $\mathrm{p}=0.213)$.

\section{Discussion}

$\mathrm{I}^{\mathrm{n}}$ $\mathrm{n}$ the acute management of pelvic ring fractures, a pelvic circumferential compression device is recommended as one of the first steps for prompt and easy stabilization of hemodynamically unstable patients ${ }^{6,30}$. However, only limited scientific evidence is available to support this recommendation. For most patients in whom a pelvic fracture is suspected, current guidelines recommend the application of a pelvic circumferential compression device. The exact behavior of the fracture fragments after application and tensioning of a pelvic circumferential compression device remains unknown, so this cadaver study was performed to assess the quality of reduction by pelvic circumferential compression devices in different types of pelvic ring fractures.

No clinically important displacement of the fracture fragments was observed when any of the pelvic circumferential compression devices were applied for Tile type-A fractures. Complete reduction was observed after application and tensioning of all three pelvic circumferential compression devices in Tile type-B1 (50-mm) fractures. In these fractures, the T-POD required the lowest mean pulling force (i.e., $40 \mathrm{~N}$ ) to achieve complete reduction of the laterally displaced os pubis. In Tile type-B1 $(100-\mathrm{mm})$ fractures, the remaining diastasis at the symphysis pubis was $<5 \mathrm{~mm}$ compared with the initial reference coordinates after application of the Pelvic Binder and T-POD. A diastasis of $7 \mathrm{~mm}$ in the symphysis pubis remained after application of the SAM Sling. However, diastasis of $\leq 10 \mathrm{~mm}$ is considered normal ${ }^{20}$ and unlikely to be clinically relevant. Following application and tensioning of the pelvic circumferential compression devices in Tile type- $C$ fractures, a mean anterior displacement of $5 \mathrm{~mm}$ of the fractured hemipelvis was observed. Anteriorly, the symphysis pubis closed with a slight overreduction in all three devices, although this is unlikely to be clinically relevant. More importantly, no significant displacement was observed at the sacroiliac joint. Even in Tile type-C fractures, the sacroiliac joint displacement was $<5 \mathrm{~mm}$.

The average lateral displacement in type-B1 $(50-\mathrm{mm})$ and B1 $(100-\mathrm{mm})$ fractures after removal of the rib spreader was approximately $20 \mathrm{~mm}$. This was due to passive recoil in a cadaveric pelvic fracture model as previously reported by Gardner et al. ${ }^{31}$. They showed that, in anteroposterior compression fractures (corresponding to Tile type $\mathrm{B}$ ), the amount of recoil was consistent regardless of the severity of maximal injury.

Biomechanical research on the quality of reduction with pelvic circumferential compression devices is limited. DeAngelis et al. ${ }^{20}$ created rotationally unstable pelvic fractures (Tile type B1) in twelve cadavers and showed that the T-POD was more effective in reducing symphysis diastasis than was a circumferential sheet. They defined a symphysis diastasis of $<10 \mathrm{~mm}$ as normal. In nine of twelve pelvic specimens, the T-POD was able to reduce the mean symphysis diastasis to $7.1 \mathrm{~mm}$ (95\% confidence interval, -2.2 to $16.4 \mathrm{~mm}$ ). In the current study, a reduction in diastasis to a clinically acceptable $<10 \mathrm{~mm}$ was achieved in all fracture types and with each type of pelvic circumferential compression device.

The results of the Vicon measurements showed that most of the displacement during compression with a circumferential compression device on the pelvic ring is in the mediolateral direction at the symphysis pubis.

There is ongoing controversy regarding the required pulling force for optimal pelvic reduction with use of pelvic circumferential compression devices. In the prospective cohort study by Krieg et al. ${ }^{3}$, radiographs were analyzed in order to quantify pelvic reduction following application of a pelvic circumferential compression device compared with pelvic reduction after definitive stabilization. A 140-N tension-limited device was used to ensure safe application of the pelvic circumferential compression device around the trochanters. This pulling force was chosen to be $20 \%$ lower than the $180-\mathrm{N}$ tension level reported in the cadaveric study by Bottlang et al. ${ }^{25}$. In the current study, the Autostop buckle of the SAM Sling (150-N tension limitation) accounted for an incomplete fracture reduction in Tile type-B1 $(100-\mathrm{mm})$ fractures at the location of the symphysis pubis in a mediolateral direction and caused overreduction in the Tile type-B1 (50-mm) and C fractures.

Bottlang et $\mathrm{al}^{25}$ measured the minimum strap tension with a prototype pelvic strap in order to achieve complete reduction of the displacement in a cadaveric study. Symphyseal contact was confirmed with a symphysis pubis sensor. This minimum strap tension was a mean of $177 \pm 44 \mathrm{~N}$ and $180 \pm 50 \mathrm{~N}$ in the partially stable and unstable pelves, respectively. This pulling force was markedly higher than the pulling forces necessary for complete reduction of Tile type-B1 or Tile type-C fractures in the current study. The required pulling force to attain complete reduction varied substantially among the three different pelvic circumferential compression devices. The T-POD reached the same reduction as the other pelvic circumferential compression devices with use of the lowest pulling force. A significant difference in the required pulling force was noted between the Pelvic Binder and the T-POD. The differences in the required pulling forces for reduction are influenced by the design of the closure mechanisms of the three pelvic circumferential compression devices, the influence of the pulley-blocks (i.e., T-POD), and the friction caused (i.e., Pelvic Binder and SAM Sling). The Pelvic Binder and the T-POD are available as "one size fits all" and need to be cut to fit before application, so their application can be more time-consuming than the sized-to-fit SAM Sling that is available in three fixed sizes. Furthermore, the Pelvic Binder and the T-POD do not provide feedback on the applied force. Both manufacturers prescribe that the straps should be pulled until two fingers just fit between the binder and the patient. The SAM Sling, on the other hand, has an Autostop buckle that limits tension to $150 \mathrm{~N}$. The results of the current study indicate that these guidelines result in clinically sufficient pulling force to reduce the displacement in pelvic fractures with the three pelvic circumferential compression devices.

The straightforward and quick method for application of circumferential compression with a pelvic circumferential com- 
The Journal of Bone \& Joint Surgery · Jbjs.org Volume 93-A • Number $3 \cdot$ February 2, 2011
Comparison of Three Different Pelvic

Circumferential Compression Devices pression device makes the use of these devices at the accident scene uncomplicated. However, the ideal pelvic circumferential compression device should provide enough circumferential compression to maximally reduce the displacement, without gross overcompression. Tissue damage is thought to occur when the exerted pressure on the skin exceeds $9.3 \mathrm{kPa}$ for more than two to three hours continuously ${ }^{32}$. A drawback of the pressure needed to accomplish pelvic ring reduction is the increased risk of skin problems ${ }^{33}$. Although pelvic circumferential compression devices are clinically effective in early fracture reduction, the development of pressure sores and complications of associated softtissue injury have been reported ${ }^{34-37}$.

Each of the pelvic circumferential compression devices uses different pulley mechanisms, so the applied pulling force does not necessarily relate to the circumferential exerted pressure under the device. As noted above, the pressure on the skin is clinically the limiting factor. No conclusions about the risk for pressure-induced skin necrosis can be drawn from this study. An inherent limitation in this study was the use of embalmed cadavers, causing the tissues to be much stiffer than normal. These cadaveric specimens may not be truly representative of all or even most pelvic fractures and could affect tissue recoil and diastasis reduction.

In conclusion, the Pelvic Binder, SAM Sling, and T-POD provided sufficient reduction in partially stable and unstable pelvic fractures. There was no adverse overreduction with any of these pelvic circumferential compression devices in Tile
type-A, B1, and C fractures. The required pulling force to attain complete reduction was lowest for the T-POD. The efficacy of pelvic circumferential compression devices in patients with pelvic ring fractures remains to be determined.

Note: The authors thank Yvonne Steinvoort (Department of Anatomy and Neurosciences, Erasmus MC, University Medical Center Rotterdam, Rotterdam, The Netherlands) for her valuable assistance in the tissue fixation and preparation of the pelvic specimens: Wibeke van Leeuwen (Detance in the tissue fixation and preparation of the pelvic specimens; Wibeke van Leeuwen (Deher support with the radiography; and Alex Brouwer (Department of Experimental Medical Instrumentation, Erasmus MC. University Medical Center Rotterdam, Rotterdam, The Netherlands) for the design and manufacturing of the stainless steel pins with retroreflective markers. The pelvic circumferential compression devices used for this study were provided by Pelvic Binder (Pelvic Binder), Innoventa BV (SAM Sling), and Rescue 3000 BV (T-POD).

S.P. Knops, MSc

N.W.L. Schep, MD, PhD, MSc

C.W. Spoor, $\mathrm{PhD}$

M.P.J.M. van Riel, MSc

W.R. Spanjersberg, MD

G.J. Kleinrensink, $\mathrm{PhD}$

E.M.M. van Lieshout, $\mathrm{PhD}$

P. Patka, MD, PhD

I.B. Schipper, $\mathrm{MD}, \mathrm{PhD}$

Departments of Surgery-Traumatology (S.P.K., N.W.L.S., W.R.S.,

E.M.M.v.L., P.P., and I.B.S.) and Neurosciences and Anatomy

(C.W.S., M.P.J.M.v.R., and G.J.K.), Erasmus MC,

University Medical Center Rotterdam,

P.O. Box 2040, 3000 CA, Rotterdam,

The Netherlands.

E-mail address for E.M.M. van Lieshout: e.vanlieshout@erasmusmc.nl

\section{References}

1. McMurtry R, Walton D, Dickinson $D$, Kellam J, Tile M. Pelvic disruption in the polytraumatized patient: a management protocol. Clin Orthop Relat Res. 1980; 151:22-30.

2. Grotz MR, Allami MK, Harwood P, Pape HC, Krettek C, Giannoudis PV. Open pelvic fractures: epidemiology, current concepts of management and outcome. Injury. 2005;36:1-13.

3. Krieg JC, Mohr M, Ellis TJ, Simpson TS, Madey SM, Bottlang M. Emergent stabilization of pelvic ring injuries by controlled circumferential compression: a clinical trial. J Trauma. 2005;59:659-64.

4. Stover MD, Summers HD, Ghanayem AJ, Willber JH. Three-dimensional analysis of pelvic volume in an unstable pelvic fracture. J Trauma. 2006;61:905-8.

5. Croce MA, Magnotti LJ, Savage SA, Wood GW 2nd, Fabian TC. Emergent pelvic fixation in patients with exsanguinating pelvic fractures. J Am Coll Surg. 2007;204: 935-42.

6. White $\mathrm{CE}, \mathrm{Hsu} \mathrm{JR}$, Holcomb JB. Haemodynamically unstable pelvic fractures. Injury. 2009;40:1023-30.

7. Pohlemann T, Culemann U, Tosounidis G, Kristen A. [Application of the pelvic C-clamp]. Unfallchirurg. 2004;107:1185-91. German.

8. Quintero AJ, Tarkin IS, Pape HC. Case report: the prone reduction of a sacroiliac disruption with a pelvic C-clamp. Clin Orthop Relat Res. 2009;467:1103-6.

9. Reynolds $\mathrm{JH}$, Attum B, Acland RJ, Giannoudis P, Roberts CS. Anterior versus posterior pin placement of pelvic C-clamp in relationship to anatomical structures: a cadaver study. Injury. 2008;39:865-8.

10. Richard MJ, Tornetta $P$ 3rd. Emergent management of APC-2 pelvic ring injuries with an anteriorly placed C-clamp. J Orthop Trauma. 2009;23:322-6.

11. Ponsen KJ, Hoek van Dijke GA, Joosse P, Snijders CJ. External fixators for pelvic fractures: comparison of the stiffness of current systems. Acta Orthop Scand. 2003;74:165-71.

12. Gardner MJ, Nork SE. Stabilization of unstable pelvic fractures with supraacetabular compression external fixation. J Orthop Trauma. 2007;21:269-73.
13. Simpson T, Krieg JC, Heuer F, Bottlang M. Stabilization of pelvic ring disruptions with a circumferential sheet. J Trauma. 2002;52:158-61.

14. Routt ML Jr, Falicov A, Woodhouse E, Schildhauer TA. Circumferential pelvic antishock sheeting: a temporary resuscitation aid. J Orthop Trauma. 2006;20 (1 Suppl):S3-6.

15. Gardner MJ, Parada S, Chip Routt ML Jr. Internal rotation and taping of the lower extremities for closed pelvic reduction. J Orthop Trauma. 2009;23:361-4.

16. Spanjersberg WR, Knops SP, Schep NW, van Lieshout EM, Patka P, Schipper IB. Effectiveness and complications of pelvic circumferential compression devices in patients with unstable pelvic fractures: a systematic review of literature. Injury. 2009;40:1031-5.

17. Friese G, LaMay G. Emergency stabilization of unstable pelvic fractures. Emerg Med Serv. 2005;34:65, 67-71.

18. Nunn T, Cosker TD, Bose D, Pallister I. Immediate application of improvised pelvic binder as first step in extended resuscitation from life-threatening hypovolaemic shock in conscious patients with unstable pelvic injuries. Injury. 2007; 38:125-8.

19. Bottlang M, Krieg JC. Introducing the pelvic sling. Pelvic fracture stabilization made simple. JEMS. 2003;28:84-93.

20. DeAngelis NA, Wixted JJ, Drew J, Eskander MS, Eskander JP, French BG. Use of the trauma pelvic orthotic device (T-POD) for provisional stabilisation of anterior-posterior compression type pelvic fractures: a cadaveric study. Injury. 2008;39:903-6.

21. Ghaemmaghami V, Sperry J, Gunst M, Friese R, Starr A, Frankel H, Gentilello LM, Shafi S. Effects of early use of external pelvic compression on transfusion requirements and mortality in pelvic fractures. Am J Surg. 2007;194:720-3.

22. FitzPatrick MK. A new tool for initial stabilization of pelvic fractures: the TPOD_Trauma Pelvic Orthotic Device. J Trauma Nurs. 2002;9:20-1.

23. Vermeulen $B$, Peter R, Hoffmeyer $P$, Unger PF. Prehospital stabilization of pelvic dislocations: a new strap belt to provide temporary hemodynamic stabilization. Swiss Surg. 1999;5:43-6. 
The Journal of Bone \& Joint Surgery - jbjs.org Volume 93-A · Number $3 \cdot$ February 2, 2011

24. Ward LD, Morandi MM, Pearse M, Randelli P, Landi S. The immediate treatment of pelvic ring disruption with the pelvic stabilizer. Bull Hosp Jt Dis. 1997;56:104-6.

25. Bottlang M, Simpson T, Sigg J, Krieg JC, Madey SM, Long WB. Noninvasive reduction of open-book pelvic fractures by circumferential compression. J Orthop Trauma. 2002;16:367-73.

26. Qureshi A, McGee A, Cooper JP, Porter KM. Reduction of the posterior pelvic ring by non-invasive stabilisation: a report of two cases. Emerg Med J. 2005;22:885-6.

27. Mahid SS, Hornung CA, Minor KS, Turina M, Galandiuk S. Systematic reviews and meta-analysis for the surgeon scientist. Br J Surg. 2006;93:1315-24.

28. Tile M, Helfet DL, Kellam JF. Fractures of the pelvis and acetabulum. 3rd ed. Philadelphia: Lippincott Williams \& Wilkins; 2003.

29. Bottlang M, Krieg JC, Mohr M, Simpson TS, Madey SM. Emergent management of pelvic ring fractures with use of circumferential compression. J Bone Joint Surg Am. 2002;84 Suppl 2:43-7.

30. American College of Surgeons. Advanced trauma life support for doctors, ATLS Guidelines. 8th ed. Chicago: American College of Surgeons; 2008.
Comparison of Three Different Pelvic

Circumferential Compression Devices

31. Gardner MJ, Krieg JC, Simpson TS, Bottlang M. Displacement after simulated pelvic ring injuries: a cadaveric model of recoil. J Trauma. 2010;68:159-65.

32. Hedrick-Thompson JK. A review of pressure reduction device studies. J Vasc Nurs. 1992;10:3-5.

33. Jowett AJ, Bowyer GW. Pressure characteristics of pelvic binders. Injury. 2007; 38:118-21.

34. Schaller TM, Sims S, Maxian T. Skin breakdown following circumferential pelvic antishock sheeting: a case report. J Orthop Trauma. 2005;19:661-5.

35. Krieg JC, Mohr M, Mirza AJ, Bottlang M. Pelvic circumferential compression in the presence of soft-tissue injuries: a case report. J Trauma. 2005;59:470-2.

36. Lerner A, Fodor L, Keren Y, Horesh Z, Soudry M. External fixation for temporary stabilization and wound management of an open pelvic ring injury with extensive soft tissue damage: case report and review of the literature. J Trauma. 2008;65:715-8.

37. Phillips TJ, Jeffcote B, Collopy D. Bilateral Morel-Lavallée lesions after complex pelvic trauma: a case report. J Trauma. 2008;65:708-11. 